\title{
Clinical course and prognostic factors of patients in severe accidental hypothermia with circulatory instability rewarmed with veno-arterial ECMO - an observational case series study
}

Sylweriusz Kosiński ${ }^{1,2}$, Tomasz Darocha ${ }^{3,4^{*}}$, Anna Jarosz ${ }^{5}$, Aleksander Zeliaśs,6, Mirosław Ziętkiewicz ${ }^{5}$, Paweł Podsiadło ${ }^{4,7}$, Tomasz Sanak ${ }^{8,9}$, Kinga Sałapa ${ }^{10}$, Jacek Piątek ${ }^{11}$, Janusz Konstany-Kalandyk ${ }^{11}$, Robert Gałązkowski ${ }^{4,12}$, Paweł Krawczyk ${ }^{5}$, Łukasz Krzych ${ }^{3}$ and Rafał Drwiła ${ }^{5}$

\begin{abstract}
Background: Recently, veno-arterial extracorporeal membrane oxygenation (VA-ECMO) has become the rewarming treatment of choice in hypothermic cardiac arrest. The detailed indications for extracorporeal rewarming in non-arrested, severely hypothermic patients with circulatory instability have not been established yet. The primary purpose of the study was a preliminary analysis of all aspects of the treatment process, as well as initial identification of mortality risk factors within the group of severely hypothermic patients, treated with arteriovenous extracorporeal membrane oxygenation (VA-ECMO). The secondary aim of the study was to evaluate efficacy of VA-ECMO in initial 6-h period of treatment

Methods: From July 2013 to June 2016, thirty one hypothermic patients were accepted for extracorporeal rewarming at Severe Accidental Hypothermia Center, Cracow. Thirteen patients were identified with circulatory instability and were enrolled in the study. The evaluation took into account patients' condition on admission, the course of therapy, and changes in laboratory and hemodynamic parameters.
\end{abstract}

Results: Nine out of 13 analyzed patients survived (69\%). Patients who died were older, had lower both systolic and diastolic pressure, and had increased creatinine an potassium levels on admission. In surviving patients, arterial blood gases parameters $\left(\mathrm{pH}, \mathrm{BE}, \mathrm{HCO}_{3}\right)$ and lactates would normalize more quickly. Their potassium level was lower on admission as well. The values of the core temperature on admission were comparable. Although normothermia was achieved in 92\% of patients, none of them had been weaned-off VA-ECMO in the first $6 \mathrm{~h}$ of treatment.

Discussion and Conclusions: In our preliminary study more pronounced markers of cardiocirculatory instability and organ hypoperfusion were observed in non-survivors. Future studies on indications to extracorporeal rewarming in severely hypothermic, non-arrested patients should focus on the extent of hemodynamic disturbances. Short term $(<6 \mathrm{~h})$ treatment in severe hypothermic, non-arrested patients seems to be not clinically appropriate.

Keywords: Critical care, Extracorporeal membrane oxygenation, Hypothermia, Rewarming, Shock

\footnotetext{
* Correspondence: tomekdarocha@wp.pl

${ }^{3}$ Department of Anaesthesiology and Intensive Care, Medical University of

Silesia, ul. Ziołowa 45/47, 40-635 Katowice, Ochojec, Poland

${ }^{4}$ Polish Medical Air Rescue, Warsaw, Poland

Full list of author information is available at the end of the article
} 


\section{Background}

The hypothermia-induced circulatory failure is multifactorial. In the course of cooling dehydration, fluid shifts, and increased urine output deplete the intravascular volume and cause haemoconcentration. In severe hypothermia the decrease in heart rate and rhythm disturbances result in fall in cardiac output (CO). Systemic vascular resistance falls as catecholamine release is blunted [1]. The further decrease of cardiac output may result from cardiac contractile dysfunction [2]. During and after rewarming, a hypothermiainduced cardiac failure ranging from mild reduction of $\mathrm{CO}$ to the fulminant circulatory shock is referred to as rewarming shock [3].

Recently, veno-arterial extracorporeal membrane oxygenation (VA-ECMO) has become the rewarming treatment of choice to be instituted in the presence of hypothermic cardiac arrest or severe circulatory instability [4-6]. One of the major advantages of VA-ECMO seems to be possibility of prolonging cardiorespiratory support if required after rewarming e.g. continuing circulatory instability, arrhythmias or impaired tolerance for the low-flow state $[4,7,8]$.

Due to low availability of extracorporeal life support (ECLS) equipment, few centers worldwide undertake extracorporeal rewarming attempts in patients with accidental hypothermia. One of the few such centers is Severe Hypothermia Treatment Center (SHTC) established in Cracow, Poland. Since all stages of diagnostics and treatment have been based on the same original protocol, there is a unique opportunity to conduct an initial comparative data analysis of patients treated under the same conditions in one center in a relatively short period of time [9].

The use of ECLS for HT III patients (core temperature $<28{ }^{\circ} \mathrm{C}$, not in cardiac arrest) may be considered in the several situations [4], but the detailed indications for VAECMO rewarming in this group of patients have not been established yet. Thus, the primary aim of the study was a preliminary analysis of all aspects of the treatment process, as well as initial identification of mortality risk factors in patients with cardiocirculatory instability in the course of severe accidental hypothermia treated with VA-ECMO.

The secondary aim of the study was to evaluate efficacy of VA-ECMO in initial 6-h of treatment, which - at least in theory, taking into account achievable rate of rewarming, should allow for stabilization of core temperature and cardiocirculatory disturbances.

\section{Methods}

From November 2013 to June 2016, 31 severely hypothermic patients (core temperature $<28{ }^{\circ} \mathrm{C}$ ) have been rewarmed with VA-ECMO. Twelve of them fulfilled the criteria of cardiocirculatory instability (systolic blood pressure $<90 \mathrm{mmHg}$ and/or life-threatening arrhythmia) $[4,5]$. One patient was admitted with core temperature $29,0^{\circ} \mathrm{C}$, but met all other clinical criteria of inclusion. Two patients suffered from cardiac arrest (ventricular fibrillation) during transport to the center, but in both cases circulation had been restored after short duration cardiopulmonary resuscitation (in 8th and 15th minute). Therefore, 13 patients were included in this study. Hypothermia was consecutive of urban exposure in all patients.

Vascular access was obtained via the femoral artery and vein with 22-24 Fr venous and 17-21 Fr arterial cannulas (Bioline Coating, Maquet, Rastatt Germany). The Rotaflow Console REF 706037 (Maquet, Rastatt, Germany) unit, with Heat Unit HU 35 heat exchanger and oxygenator (Permanent Life Support Set, Maquet, Rastatt, Germany) was used in all cases.

The clinical characteristics of 13 analyzed patients included: sex, age, type of exposure, type and distance of transport, vital signs on arrival (heart rhythm, core temperature, blood pressure, type of arrhythmia), complications during Intensive Care Unit (ICU) stay, catecholamine use (dose and duration of treatment), duration of mechanical ventilation, duration of VA-ECMO treatment, rate of rewarming, left ventricular ejection fraction (LVEF) on discharge and survival rate. The clinical characteristics of the group are presented in Table 1.

Comparison of clinical parameters between survivors and non-survivors included core temperature $(\mathrm{Tc})$, blood pressure and end-tidal carbon dioxide $\left(\mathrm{EtCO}_{2}\right)$ at admission, as well as parameters of acid-base balance $(\mathrm{pH}$, $\mathrm{pCO}_{2}, \mathrm{pO}_{2}$, base deficit), lactate level and clearance, serum glucose, electrolytes and creatinine, levels of creatine kinase, creatine kinase-MB and high sensivity troponin $\mathrm{T}$ (hsTnT), hemoglobin level and coagulation profile.

Blood samples were collected for the blood glucose and chemistry analysis at the time of admission and according to accepted schedule. Arterial blood gas analysis according to alpha-stat strategy (corrected to the normal body temperature) was assessed on admission and on 2, 4, 6, 8, $10,12,16,20,24 \mathrm{~h}$ of ICU stay. Blood tests were assayed by routine automated laboratory techniques (Cobas System 600, Roche Diagnostics GmbH, Manheim, Germany). All biochemical analyses were performed in the central hospital laboratory, certified with a cardiac and clinical chemistry program by RIQAS (Randox Quality Assessment Scheme, UK). Lactate clearance was calculated as followed [10]: $\left[\left(\right.\right.$ lactate $_{\text {initial }}-$ lactate $\left._{\text {delayed }}\right) /$ lactate $\left.\left._{\text {initial }}\right] \times 100 \%\right]$.

Due to a small sample included in the study, the statistical analysis has been limited to presentation of descriptive statistics. Categorical variables were presented as numbers of subjects and percentages. Continuous variables were analyzed for normal distribution using 
Table 1 Characteristics and outcomes of the 13 patients in severe accidental hypothermia with cardiocirculatory instability

\begin{tabular}{|c|c|}
\hline Sex: Male & $10(77 \%)$ \\
\hline Age [years] & Me 60; IQR [56-66] \\
\hline Urban-type hypothermia & $13(100 \%)$ \\
\hline Distance of transport [km] & Me 14, IQR [7-82] \\
\hline \multicolumn{2}{|l|}{ Type of Transport } \\
\hline HEMS & $2(15 \%)$ \\
\hline Ambulance & $10(77 \%)$ \\
\hline ECMO team to the patient & $1(8 \%)$ \\
\hline Tc on admission $\left[{ }^{\circ} \mathrm{C}\right]$ & $25.8 \pm 2.1(20.7-29.0)$ \\
\hline HR on admission $\left[\mathrm{min}^{-1}\right]$ & $53 \pm 12.9(40-80)$ \\
\hline $\mathrm{SBP}[\mathrm{mmHg}]$ & Me $70(50-80)$ \\
\hline $\mathrm{DBP}[\mathrm{mmHg}]$ & Me 40 (30-60) \\
\hline \multicolumn{2}{|l|}{ Heart rhythm on admission } \\
\hline Sinus rhythm & $8(62 \%)$ \\
\hline Atrial fibrillation & $2(15 \%)$ \\
\hline Junctional rhythm & $3(23 \%)$ \\
\hline \multicolumn{2}{|l|}{ Complications during ICU stay } \\
\hline Aspiration Pneumonia & $1(8 \%)$ \\
\hline Lower Limb Ischemia & $3(23 \%)$ \\
\hline Bleeding from Upper GI Tract & $3(23 \%)$ \\
\hline Alcohol Withdrawal Syndrome & $4(31 \%)$ \\
\hline Kidney Failure & $3(23 \%)$ \\
\hline \multicolumn{2}{|l|}{ Cathecholamine use } \\
\hline Adrenaline & $\begin{array}{l}4(31 \% ; \text { mean dose } \\
0.16 \mathrm{ug} / \mathrm{kg} / \mathrm{min})\end{array}$ \\
\hline Noradrenaline & $\begin{array}{l}9 \text { (69\%; mean dose } \\
1.7 \mathrm{ug} / \mathrm{kg} / \mathrm{min})\end{array}$ \\
\hline Dopamine & $\begin{array}{l}2(15 \% ; \text { mean dose } \\
15 \mathrm{ug} / \mathrm{kg} / \mathrm{min})\end{array}$ \\
\hline Dobutamine & $\begin{array}{l}3(23 \% ; \text { mean dose } \\
16.7 \mathrm{ug} / \mathrm{kg} / \mathrm{min})\end{array}$ \\
\hline More than 1 cathecholamine used & $5(38 \%)$ \\
\hline Cathecholamine administration [days] & Me 2 IQR [1-7] \\
\hline Duration of mechanical ventilation [days] & Me 2 IQR $[1,3-7,9]$ \\
\hline Duration of VA-ECMO [hours] & Me 23 IQR [19-32] \\
\hline Rate of rewarming [C/hrs.] & Me 1,8 IQR $[1,5-3,0]$ \\
\hline Duration of stay in the ICU [days] & Me 3 IQR $[2,0-9,0]$ \\
\hline LVEF on discharge [\%] & $56 \pm 8(40-65)$ \\
\hline Survived & $9(69 \%)$ \\
\hline
\end{tabular}

$M$ denotes mean value; Me median, IQR interquartile interval

the Shapiro-Wilk test and were presented as mean plus standard deviation and minimum and maximum for normal distribution and were presented as median values $(\mathrm{Me})$ with lower and upper quartiles (IQR) for non-normal distribution.

\section{Results}

The comparison of clinical parameters and outcomes of survivors and non-survivors are presented in Table 2 . Patients who died were older, with lower blood pressure and biochemical parameters abnormalities reflecting severe organ hypoperfusion, including significantly increased potassium level and more than doubled creatinine concentrations. The clinical characteristics of non-survivors, including time and cause of death are presented in Table 3. In survivors, arterial blood gas parameters $\left(\mathrm{pH}, \mathrm{BE}, \mathrm{HCO}_{3}{ }^{-}\right)$and lactates normalized faster. Lactate clearance in the first $24 \mathrm{~h}$ of ICU admission is presented in Fig. 1. There is also a considerable difference between end-tidal $\mathrm{CO}_{2}$ and arterial blood gas $\mathrm{CO}_{2}$ partial pressure on admission of about $20 \mathrm{mmHg}$ (Table 2).

After $6 \mathrm{~h}$ of therapy, normothermia was achieved in 12 patients (92.3\%). None of the patients had been weaned off ECMO within the first $6 \mathrm{~h}$ of treatment. The outcome of 13 patients after $6 \mathrm{~h}$ of VA-ECMO treatment are presented in Table 4.

\section{Discussion}

In our study we have attempted to indicate unfavorable prognostic factors in a small, but uniform group of severely hypothermic patients with cardiocirculatory instability, treated with VA-ECMO. Those factors were: old age, low blood pressure on admission, low initial and post-warming $\mathrm{PaCO}_{2}$ partial pressure, low $\mathrm{pH}$, large base deficit, high serum creatinine, potassium and lactate levels (marked at least six hours of rewarming). However, the study sample size is too small to assess any predictive value of individual factors related to survival. Thus, the main finding of the study is that most prominent feature which distinguishes survivors and nonsurvivors in our cohort are clinical and biochemical parameters reflecting organ hypoperfusion. At the moment the clinical criteria to be considered as the indications for ECLS rewarming are: failure to improve with external active and minimally invasive rewarming methods, life-threatening arrhythmia, hypotension (systolic blood pressure $<90 \mathrm{mmHg}$ ), respiratory failure, refractory acidosis and comorbidities, which limit tolerance for the low-flow state of HT III [4]. Although our study was only observational in design and limited to small number of patients it indicates, that future studies on indications to extracorporeal rewarming in severely hypothermic, non-arrested patients should focus on the extent of hemodynamic disturbances. The mean systolic blood pressure in analyzed cohort was below $70 \mathrm{mmHg}$ despite high catecholamine doses. Mair and Ruttmann proposed a scheme in which the criteria for introducing extracorporeal rewarming in non-arrested, severely hypothermic patients was $\mathrm{SBP} \leq 60 \mathrm{mmHg}$ 
Table 2 Characteristics of survivors and non-survivors

\begin{tabular}{|c|c|c|}
\hline Parameter & Survivors $(n=9)$ & Non-survivors $(n=4)$ \\
\hline Age [years] & Me 57 IQR [55-60] & Me 73 IQR [64.5-82.5] \\
\hline Tc at hospital admission $\left[{ }^{\circ} \mathrm{C}\right]$ & $26.07 \pm 1.51$ & $25.32 \pm 3.24$ \\
\hline SBP at hospital admission [mmHg] & $74.4 \pm 8.82$ & $57.5 \pm 5$ \\
\hline DBP at hospital admission $[\mathrm{mmHg}]$ & $47.2 \pm 7.55$ & $35 \pm 5.77$ \\
\hline $\mathrm{pH}$ at hospital admission & $7.14 \pm 0.08$ & $7.02 \pm 0.15$ \\
\hline $\mathrm{pH}$ after achieving normothermia & Me 7.32 IQR [7.32-7.33] & Me 7.23 IQR [7.03-7.32] \\
\hline $\mathrm{EtCO}_{2}$ at hospital admission & $17.3 \pm 1.5$ & $14.5 \pm 2.5$ \\
\hline $\mathrm{PaCO}_{2}$ at hospital admission $[\mathrm{mmHg}]$ & $41.4 \pm 8.2$ & $26.4 \pm 7.4$ \\
\hline $\mathrm{PaCO}_{2}$ after achieving normothermia $[\mathrm{mmHg}]$ & Me 31.4 IQR [28.7-31.8] & Me 24.5 IQR [19.2-29.6] \\
\hline $\mathrm{PaO}_{2}$ at hospital admission $[\mathrm{mmHg}]$ & $232.5 \pm 117.7$ & $107.6 \pm 50.7$ \\
\hline Lactate level (mmol/l) at hospital admission & $6.89 \pm 5.94$ & $12.57 \pm 4.55$ \\
\hline Lactate level $(\mathrm{mmol} / \mathrm{l})$ after achieving normothermia & Me 2.9 IQR [1.4-3.6] & Me 12.2 IQR [8.4-15.3] \\
\hline Lactate clearance $6 \mathrm{~h}$ & $46.9 \%$ & $5.7 \%$ \\
\hline Lactate clearance $24 \mathrm{~h}$ & $73.0 \%$ & $34.8 \%$ \\
\hline Lactate clearance at normothermia & $56.0 \%$ & $5.7 \%$ \\
\hline BE at hospital admission [mEq/L] & $-14.322 \pm 4.82$ & $-23.45 \pm 4.33$ \\
\hline BE after achieving normothermia [mEq/L] & Me -9.2 IQR [-11.4 - -7.7] & Me -14 IQR [-22.1- -12.1] \\
\hline $\mathrm{HCO}_{3}$ at hospital admission $[\mathrm{mmol} / \mathrm{L}]$ & $13.889 \pm 4.09$ & $7.225 \pm 1.63$ \\
\hline $\mathrm{HCO}_{3}$ after achieving normothermia $[\mathrm{mmol} / \mathrm{L}]$ & $16.389 \pm 3.37$ & $9.850 \pm 4.78$ \\
\hline K at hospital admission [mmol/L] & $3.022 \pm .76$ & $4.975 \pm .85$ \\
\hline $\mathrm{Na}$ at hospital admission [mmol/L] & $137.6 \pm 6.4$ & $143.2 \pm 16.1$ \\
\hline Glucose at hospital admission [mmol/L] & $8.2 \pm 2.97$ & $6.1 \pm 1.07$ \\
\hline Creatinine at hospital admission $[\mu \mathrm{mol} / \mathrm{L}]$ & Me 85 IQR [64-114] & Me 194 IQR [139-376] \\
\hline CK at hospital admission [U/L] & Me 1374 IQR [1114-2397] & Me 4664 IQR [1724-18054] \\
\hline CK 6 h $[U / L]$ & Me 1195 IQR [495-4168] & Me 1948 IQR [595-6830] \\
\hline CK-MB at hospital admission [U/L] & Me 115 IQR [100-132] & Me 278 IQR [164-394] \\
\hline CK-MB 6 h [U/L] & Me 70 IQR [54-183] & Me 180 IQR [125--249] \\
\hline hsTnT at hospital admission [nmol/L] & Me 0.033 IQR [0.027-0.048] & Me 0.082 IQR [0.073-0.203] \\
\hline hsTnT 6 h [nmol/L] & Me 0.064 IQR [0.038-0.372] & Me 0.097 IQR [0.091-0.17] \\
\hline INR at hospital admission & $1.46 \pm .28$ & $1.61 \pm .23$ \\
\hline APTT $0 \mathrm{~h}$ & $37.7 \pm 10.7$ & $35.9 \pm 15.1$ \\
\hline PLT at hospital admission $\left[10^{3} / \mathrm{uL}\right]$ & $142 \pm 66$ & $124 \pm 110$ \\
\hline $\mathrm{Hb}$ at hospital admission [g/dl] & $12.13 \pm 4.0$ & $10.90 \pm 3.66$ \\
\hline $\mathrm{Hb}$ after achieving normothermia [g/dl] & $9.54 \pm 1.94$ & $9.15 \pm 1.21$ \\
\hline
\end{tabular}

Continuous data presented with mean value with standard deviation (normal distribution) or as median with lower and upper quartiles (non-normal distribution). $M$ denotes mean value; Me median, IQR interquartile interval

Table 3 The clinical characteristics of non-survivors

\begin{tabular}{lllll}
\hline Sex/age (years) & TC $\left({ }^{\circ} \mathrm{C}\right)$ & $\begin{array}{l}\text { VA ECMO treatment } \\
\text { (hours) }\end{array}$ & $\begin{array}{l}\text { Time of death } \\
\text { (hours since admission) }\end{array}$ & Cause of death \\
\hline M/66 & 20.7 & 42 & 216 & gastrointestinal bleeding, hepatic failure, multiple organ failure \\
F/81 & 25.6 & 21 & 48 & traumatic brain injury, gastrointestinal bleeding \\
M/63 & 27.0 & 26 & 36 & methanol intoxication \\
F/84 & 28.0 & 16 & 20 & gastrointestinal bleeding, renal insufficiency \\
\hline
\end{tabular}




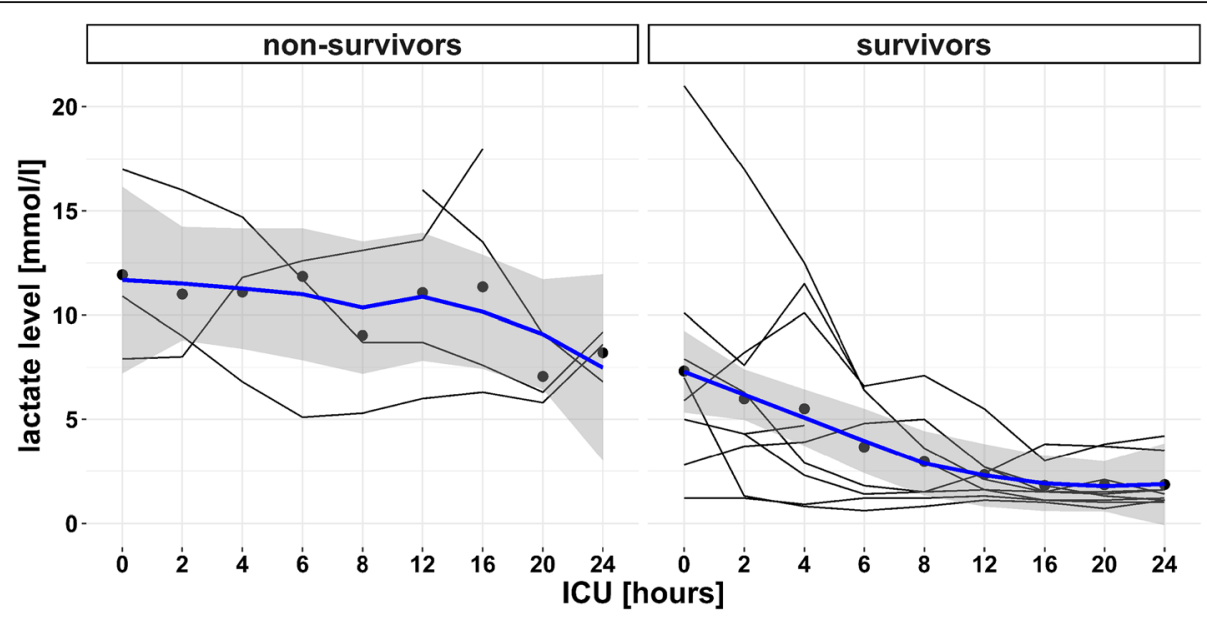

Fig. 1 Individual patient lactate level profiles in first $24 \mathrm{~h}$ of ICU stay. Dots represent mean value of lactate level in all patients arterial blood sample for the following hours. Bold lines represent smooth curve fitted by loess function with $95 \%$ confidence interval

and/or serious rhythm disorders [11]. Taking into account the results of our study and experience from SHTC, we were eager to accept those lower limits of blood pressure instead of current $<90 \mathrm{mmHg}$. At the same time, in our opinion, there should be an emphasis on acid-base balance parameters, which - if they are not stabilized or normalized in the initial phase of emergency actions - indicate serious hemodynamic disturbances in the course of hypothermia.

Mortality rate until ICU discharge in our study was $31 \%$. Vassal et al. in their study, which was also dedicated to urban-type hypothermia, reported the mortality rate of $38 \%$ with the core temperature (Tc) higher by $3{ }^{\circ}$ $\mathrm{C}$, mean systolic pressure higher by $16 \mathrm{mmHg}$, and all patients being rewarmed by non-invasive methods. Taking into account the study subgroup of patients with Tc $<29{ }^{\circ} \mathrm{C}$ (21 patients), the mortality was over 50\% [12]. When comparing the results of both studies it could be concluded, that extracorporeal rewarming can be beneficial, at least in selected group of the patients. However despite numerous case reports, observation studies, rich clinical experience and expert guidelines, there is lack of randomized controlled trials and it is difficult to present convincing, evidence-based proofs of increased survival rate in patients treated by extracorporeal rewarming. In many cases, death is caused by concomitant, chronic conditions, trauma, and/or circumstances in which hypothermia occurred (such as asphyxia in drowning or avalanche burial) [4].

Ruttman et al. identified unfavorable prognostic factors in patients in cardiac arrest rewarmed with VAECMO. A single-factor analysis indicated elevated level of potassium, lower blood $\mathrm{pH}$ on admission, and preceding asphyxia as mortality factors [7]. In the whole analyzed group, about $75 \%$ of patients were asphyxiated due to drowning or avalanche burial. It is then possible, that the results of electrolyte and acid-base abnormalities did not reveal hypothermia per se, but were related to asphyxia. However, in our cohort hypothermia was induced by environmental exposure in urban setting in all cases, without episodes of asphyxia. Thus, the results of our preliminary study correspond with the results obtained by Ruttman et al.

An additional objective of this study was to evaluate the efficacy of the initial, 6-h period of VA-ECMO rewarming. The median duration of extracorporeal treatment in our group was $23 \mathrm{~h}$ and significantly exceeded the time required for achieving normothermia. Even within the group of survivors, after six hours of treatment, the patients' circulatory parameters were not stable enough to safely wean-off VA-ECMO. The main goals of the ECLS are stabilization of the core

Table 4 Outcome of 13 patients after 6 hours of VA-ECMO treatment

\begin{tabular}{llll}
\hline Feature & Survivors & Non-survivors & Total \\
\hline Normothermia & $8 / 9(88.9 \%)$ & $4 / 4(100 \%)$ & $12 / 13(92.3 \%)$ \\
Cathecholamine support (>1 drug) & $7 / 9(77.8 \%)$ & $2 / 4(50 \%)$ & $9 / 13(69.23 \%)$ \\
$\mathrm{pH}<7.2$ & $1 / 9(11.1 \%)$ & $2 / 4(50 \%)$ & $3 / 13(23.07 \%)$ \\
Lack of lactate normalization & $6 / 9(66.7 \%)$ & $4 / 4(100 \%)$ & $10 / 13(76.92 \%)$ \\
Diuresis $<1 \mathrm{ml} / \mathrm{kg} / \mathrm{h}$ & $0 / 9(0 \%)$ & $2 / 4(50 \%)$ & $2 / 13(15.4 \%)$ \\
Fluid resuscitation volume $>3000 \mathrm{ml} / 6 \mathrm{~h}$ & $7 / 9(77.8 \%)$ & $4 / 4(100 \%)$ & $11 / 13(84.6 \%)$ \\
\hline
\end{tabular}


temperature and hemodynamic status, including cerebral perfusion, particularly in patients after cardiac arrest [4, 11]. Prompt normalization of acid-base balance parameters during the first six hours of VA-EMCO treatment may be prognostically significant, and proves the treatment to be effective, but is not clinically exhaustive. Therefore, based on our data, it seems that the use of short-term extracorporeal treatment of hypothermia, although economically cost-effective, is clinically not appropriate.

Severely hypothermic patients with cardiocirculatory instability represent a vulnerable group of patients and it is important to evaluate treatment strategies with invasive techniques, as lack of randomized studies makes causal inference of the benefit of such strategies uncertain. However, our study has a number of limitations. The small sample size affects the reliability of the findings. There was no control group with which to compare changes in parameters analyzed. The implementation of a standardized approach makes the results from this cohort study more valid, but the findings need to be interpreted with caution.

\section{Conclusions}

In our preliminary study more pronounced markers of cardiocirculatory instability and organ hypoperfusion were observed in non-survivors. Future studies on indications to extracorporeal rewarming in severely hypothermic, non-arrested patients should focus on the extent of hemodynamic disturbances. In our opinion, there should be an emphasis on acid-base balance parameters, which - if they are not stabilized or normalized in the initial phase of emergency actions - indicate serious hemodynamic disturbances in the course of hypothermia. Short term $(<6 \mathrm{~h})$ extracorporeal treatment in severe hypothermic, non-arrested patients seems to be not clinically appropriate.

\section{Abbreviations \\ APTT: Activated partial thromboplastin time; CK: Creatine kinase; CK- MB: Cardiac isoenzyme of creatine kinase; CO: Cardiac output; DBP: Diastolic blood pressure; ECLS: Extracorporeal life support; $\mathrm{EtCO}_{2}$ : End-tidal $\mathrm{CO}_{2}$; Hb: Hemoglobin; hsTnT: High sensitivity troponin; ICU: Intensive Care Unit; INR: International normalized ratio; IQR: Lower and upper quartiles; LVEF: Left ventricular ejection fraction; Me: Median values; $\mathrm{PaCO}_{2}$ : Partial pressure of $\mathrm{CO}_{2}$ in arterial blood; $\mathrm{PaO}_{2}$ : Partial pressure of $\mathrm{O}_{2}$ in arterial blood; PLT: Platelets; SBP: Systolic blood pressure; SHTC: Severe Hypothermia Treatment Centre; TC: Core body temperature; VA-ECMO: Extracorporeal membrane oxygenation arteriovenous configuration}

\section{Acknowledgements}

Not applicable.

\section{Funding}

No financial support was received for this study.

\section{Availability of data and materials}

The datasets used and/or analysed during the current study are available from the corresponding author on reasonable request.

\section{Authors' contributions}

SK: designed the study, supervised data collection, took part in manuscript preparation, contributed substantially to the revision of the manuscript, takes responsibility for the paper as a whole. TD, AJ: supervised data collection, contributed substantially to the revision of the manuscript. AZ, MZ,PP, TS, KS: contributed substantially to the revision of the manuscript. JP, JKK, RG, PK, ŁK, RD: provided advise on study design, contributed to the revision of the manuscript. All authors read and approved the final manuscript.

\section{Competing interest}

The authors declare that they have no competing interests.

\section{Consent for publication}

Written informed consent was obtained from the patients for publication of their individual details in this manuscript. The consent form is held by the authors and is available for review by the Editor-in-Chief.

\section{Ethics approval and consent to participate}

The prospective observational case-series study was approved by the Local Ethical Committee of the John Paul II Hospital in Cracow.

\section{Publisher's Note}

Springer Nature remains neutral with regard to jurisdictional claims in published maps and institutional affiliations.

\section{Author details}

'Department of Anesthesiology and Intensive Care, Pulmonary Hospital, Zakopane, Poland. ${ }^{2}$ Tatra Mountain Rescue Service, Zakopane, Poland. ${ }^{3}$ Department of Anaesthesiology and Intensive Care, Medical University of Silesia, ul. Ziołowa 45/47, 40-635 Katowice, Ochojec, Poland. ${ }^{4}$ Polish Medical Air Rescue, Warsaw, Poland. ${ }^{5}$ Department of Anesthesiology and Intensive Care, the John Paul II Hospital, Medical College of Jagiellonian University,

Cracow, Poland. ${ }^{6} \mathrm{Clinic}$ of Interventional Cardiology, Institute of Cardiology, Jagiellonian University Medical College, John Paul II Hospital, Krakow, Poland. ${ }^{7}$ Polish Society for Mountain Medicine and Rescue, Szczyrk, Poland. ${ }^{8}$ Department of Disaster Medicine and Emergency Care, Jagiellonian University Medical College, Krakow, Poland. ${ }^{9}$ Department of Combat Medicine, Military Institute, Warsaw, Poland. ${ }^{10}$ Department of Bioinformatics and Telemedicine, Jagiellonian University Medical College, Cracow, Poland. ${ }^{11}$ Department of Cardiovascular Surgery and Transplantology, Institute of Cardiology Collegium Medicum, Jagiellonian University, John Paul II Hospital, Cracow, Poland. ${ }^{12}$ Department of Emergency Medical Services, Medical University of Warsaw, Warsaw, Poland.

Received: 14 February 2017 Accepted: 25 April 2017

Published online: 02 May 2017

References

1. Dietrichs ES, Sager G, Tveita T. Altered pharmacological effects of adrenergic agonists during hypothermia. Scand J Trauma Resusc Emerg Med. 2016;24: 143. doi:10.1186/s13049-016-0339-8.

2. Darocha T, Sobczyk D, Kosiński S, et al. New diastolic cardiomyopathy in patients with severe accidental hypothermia after ECMO rewarming: a caseseries observational study. Cardiovasc Ultrasound. 2015;13:31. doi:10.1186/ s12947-015-0027-2.

3. Tveita T. Rewarming from hypothermia. Newer aspects on the pathophysiology of rewarming shock. Int J Circumpolar Health. 2000;59: 260-6.

4. Paal P, Gordon L, Strapazzon G, et al. Accidental hypothermia-an update. Scand J Trauma Resusc Emerg Med. 2016;24:111. doi:10.1186/s13049-0160303-7.

5. Truhlár A, Deakinc CD, Soar J, et al. European resuscitation council guidelines for resuscitation 2015 section 4. Cardiac arrest in special circumstances. Resuscitation. 2015;95:148-201.

6. Brown D, Brugger H, Boyd J, et al. Accidental hypothermia. N Engl J Med. 2012;367:1930-8.

7. Ruttmann $\mathrm{E}$, Weissenbacher $\mathrm{A}$, Ulmer $\mathrm{H}$, et al. Prolonged extracorporeal membrane oxygenation-assisted support provides improved survival in hypothermic patients with cardiocirculatory arrest. J Thorac Cardiovasc Surg. 2007;134:594-600. 
8. Morita S, Inokuchi S, Yamagiwa T, et al. Efficacy of portable and percutaneous cardiopulmonary bypass rewarming versus that of conventional internal rewarming for a patients with accidental deep hypothermia. Crit Care Med. 2011;39:1064-8. doi:10.1097/CCM. Ob013e31820edd04.

9. Darocha T, Kosiński S, Jarosz A, et al. Severe accidental hypothermia center. Eur J Emerg Med. 2015;22:288-91.

10. Marty $P$, Roquilly A, Vallée F, et al. Lactate clearance for death prediction in severe sepsis or septic shock patients during the first 24 hours in Intensive Care Unit: an observational study. Ann Intensive Care. 2013;3:3. doi:10.1186/ 2110-5820-3-3.

11. Vassal T, Benoit-Gonin B, Carrat F, et al. Severe accidental hypothermia treated in an ICU. Chest. 2001;120:1998-2003.

12. Mair $P$, Ruttmann E. ECMO for Severe Accidental hypothermia. (in) ECMO Extracorporeal Life Support in Adults, Springer Italia 2014, Sangalli F Patroniti N, Pesenti A (Eds); pp 163-170.

Submit your next manuscript to BioMed Central and we will help you at every step:

- We accept pre-submission inquiries

- Our selector tool helps you to find the most relevant journal

- We provide round the clock customer support

- Convenient online submission

- Thorough peer review

- Inclusion in PubMed and all major indexing services

- Maximum visibility for your research

Submit your manuscript at www.biomedcentral.com/submit
C) Biomed Central 